\title{
Interferon-inducible genes are major targets of human papillomavirus type 31: Insights from microarray analysis
}

\author{
Yijan E. Chang and Laimonis A. Laimins* \\ Department of Microbiology-Immunology, \\ Northwestern University Medical School, Chicago, IL \\ 60611, USA
}

Human papillomavirus (HPVs) are small DNA viruses that infect epithelial tissue. More than 70 subtypes of HPV have been identified to date and they exhibit specific tropism to various region of the body [11, 19,33]. Genital HPVs can be divided to high-risk and low-risk groups [19]. The high-risk genital HPVs (HPV16, 18, 31, 33, and 54) are the etiological agents of cervical cancer, whereas low-risk HPVs (HPV6 and 11) are associated with common genital warts. Cervical cancer is the second most common cancer in women world wide, resulting in 500,000 new cases and 200,000 death every year. Because of the lack of the access to routine Pap smears, cervical cancer remains a devastating disease in developing countries [15].

The genome of HPVs encodes only 8 to 10 proteins. The virus must therefore depend on basic cellular machinery to modulate cellular activities in favor of viral replication. As a result, the interaction of viral proteins with the host proteins is essential for viral replication. The best known examples include the interaction of oncoproteins E6 and E7 of high-risk HPVs with p53 and pRB, respectively. These interactions result in degradation and inactivation of p53 by E6 [12,26, 27], and inactivation of $\mathrm{pRB}$ by $\mathrm{E} 7$, resulting in altered regulation of E2F-inducible genes $[5,8,20]$. In addition to E6 and E7, HPV E2 protein has been shown to have transactivation/repression activity by binding to specific recognition sequences [3,21], and E5 protein

*Address for correspondence: Department of MicrobiologyImmunology, Northwestern University Medical School, 303 E. Chicago Ave., Chicago, IL 60611, USA. Tel.: +1 312503 0648; Fax: +1 312503 0649; E-mail: 1-laimins@ northwestern.edu. has been shown to enhance signal transduction through the EGF and PDGF receptors [16]. Such alterations are likely to have significant effects on cellular gene expression. An understanding of the virally inducedchanges in cellular gene expression would shed light on HPV viral life cycle and pathogenesis.

The HPV viral life cycle can be divided into at least two stages. The virus establishes latent infection in the basal layer of epidermis following primary infection. Upon keratinocye stratification and differentiation, the viral genome is amplified and late structural genes are synthesized, which leads to virion maturation [7]. Because of the requirement for differentiation at the late stage of viral life cycle, the lack of a good in vitro tissue culture system to propagate the virus has been a major hurdle in HPV research. Recently, a tissue culture model that mimics the latent stage of HPV infection has been developed [7,23]. Cloned HPV 31 and HPV 18 genome have been used to transfect normal human keratinocytes (NHK) resulting in cell lines that exhibit characteristics of basal keratinocytes infected with HPV. Once induced to differentiate, these cell lines are able to activate late viral functions and produce virions [10,23]. This system provides an excellent model to investigate virus-cell interactions under physiologically relevant conditions. We have been interested in examining cellular changes at the transcriptional level during the first stage of infection by HPV31. Our experimental approach has been to compare the transcriptional profile of keratinocytes containing transfected HPV31 genome, with that of normal keratinocytes by microarray analysis $[13,32]$. In order to avoid any variation resulted from specific genetic background, HPV31 cells were compared with uninfected keratinovytes from the same donor.

Microarray analysis was performed with an array containing 7,075 expressed sequence tags (ESTs), including 4,000 known genes (InCyte Human UniGem V). We observed that expression of most of the ESTs 
Table 1

Genes whose expression was altered by more than 2.4 -fold

\begin{tabular}{|c|c|c|c|c|c|}
\hline Genebank & Gene name & $\begin{array}{l}\text { Diff. } \\
\text { expr. }\end{array}$ & $\begin{array}{l}\text { Genebank } \\
\text { ID }\end{array}$ & Gene name & $\begin{array}{l}\text { Diff. } \\
\text { expr. }\end{array}$ \\
\hline M33882 & myxovirus (influenza) resistance 1 & -11.5 & X04741 & ubiquitin carboxyl-terminal esterase L1 & +3.2 \\
\hline X67325 & interferon-alpha inducible $11.5 \mathrm{KD}$ protein & -10.1 & V00571 & corticotropin releasing hormone & +3.1 \\
\hline X03557 & interferon-inducible protein 56 & -9.6 & T91294 & ESTs & +3.1 \\
\hline W76205 & ESTs & -6.9 & X16832 & cathepsin $\mathrm{H}$ & +2.9 \\
\hline S73288 & small proline-rich protein SPRK & -5.4 & M69199 & human GOS2 gene & +2.9 \\
\hline M20030 & human small proline rich protein (sprII) & -5.1 & M73548 & adenomatosis polyposis coli & +2.9 \\
\hline W73855 & ESTs & -3.9 & AA085711 & ESTs & +2.8 \\
\hline U65590 & interleukin 1 receptor antagonist & -3.9 & AA477828 & ESTs & +2.8 \\
\hline L33404 & protease, serine, 6 & -3.8 & AA705034 & ESTs, weakly similar to reverse transcriptase & +2.7 \\
\hline M34715 & pregnancy specific beta-1-glycoprotein 7 & -3.6 & R55750 & ESTs & +2.7 \\
\hline X04470 & secretory leukocyte protease inhibitor & -3.6 & AA018443 & ESTs & +2.7 \\
\hline M87284 & 2'-5' oligoadenylate synthetase 2 & -3.5 & W67951 & ESTs & +2.7 \\
\hline AA741307 & ESTs & -3.5 & AA731863 & ESTs & +2.7 \\
\hline \multirow[t]{2}{*}{ M97935 } & signal transducer and activator of transcription-1 & & AA134111 & ESTs & +2.6 \\
\hline & $\alpha / \beta$ & -3.5 & AA705184 & ESTs & +2.6 \\
\hline Y00630 & plasminogen activator inhibitor type II & -3.4 & AA524538 & succinate CoA ligase, ADP-forming, beta subunit & +2.6 \\
\hline L33930 & human CD24 gene & -3.3 & AA633231 & ESTs & +2.6 \\
\hline J04164 & interferon-inducible protein $1-8 \mathrm{U}$ & -3.3 & AA040834 & ESTs, weakly similar to collagens & +2.6 \\
\hline U50931 & defensin, beta- 1 & -3.2 & H18233 & ESTs & +2.5 \\
\hline X59770 & interleukin 1 receptor, type II & -3.2 & AA150502 & ESTs & +2.5 \\
\hline M95787 & transgelin & -3.2 & AA575973 & ESTs & +2.5 \\
\hline X99133 & neutrophil gelatinase-associated lipocalin precursor & -3.1 & AI033548 & ESTs & +2.5 \\
\hline X74330 & primase, polypeptide 1 & -3.0 & W15253 & ESTs & +2.5 \\
\hline X56807 & desmocollin 2 & -2.9 & N57571 & ESTs & +2.5 \\
\hline X82200 & human Staf50 mRNA & -2.8 & R55697 & ESTs & +2.5 \\
\hline M30818 & myxovirus (influenza) resistance 2 & -2.8 & D83884 & ESTs & +2.5 \\
\hline U92314 & sulfotransferase family $2 \mathrm{~B}$, member 1 & -2.7 & N22132 & ESTs & +2.5 \\
\hline U09364 & zinc finger protein 136 & -2.6 & AA425325 & ESTs & +2.5 \\
\hline X04327 & 2,3-bisphosphoglycerate mutase & -2.6 & AA805921 & ESTs & +2.5 \\
\hline U72882 & interferon-inducible leucine zipper protein (IFP35) & -2.6 & AA527448 & ESTs & +2.5 \\
\hline X86809 & phosphoprotein enriched in astrocytes 15 & -2.6 & AA134926 & ESTs & +2.4 \\
\hline Z85996 & CKI (p21) & -2.6 & AA683531 & ESTs & +2.4 \\
\hline L06895 & MAX dimerization protein (Mad) & -2.5 & AA648117 & ESTs & +2.4 \\
\hline M22612 & trypsin1 & -2.5 & AA733074 & ESTs, weakly similar to $\mathrm{C} 15 \mathrm{H} 9.5$ (C.elegans) & +2.4 \\
\hline U79725 & human A33 & -2.5 & AA280262 & ESTs & +2.4 \\
\hline AJ000480 & C8FW phosphoprotein & -2.5 & N52534 & ESTs & +2.4 \\
\hline M77830 & desmoplakin I and II & -2.5 & U39905 & solute carrier family 18 & +2.4 \\
\hline X89960 & mitochondrial capsule selenoprotein & -2.5 & AA056410 & ESTs, weakly similar to IgE receptor beta subunit & +2.4 \\
\hline X57348 & stratifin & -2.5 & AA190841 & ESTs & +2.4 \\
\hline M23263 & androgen receptor & -2.4 & AA846757 & ESTs & +2.4 \\
\hline AA100757 & ESTs & -2.4 & H98977 & ESTs & +2 . \\
\hline AF013970 & myeloid translocation gene-related protein 1 & -2.4 & N49233 & ESTs & +2 \\
\hline AB001928 & cathepsin L2 & -2.4 & AA557324 & ESTs, highly similar to cytochrome P450 IVA2 & +2.4 \\
\hline X13916 & low density lipoprotein-related protein 1 & -2.4 & N51427 & ESTs & +2.4 \\
\hline L34155 & laminin, alpha 3 & -2.4 & AI025984 & ESTs & +2.4 \\
\hline \multirow[t]{2}{*}{ V01512 } & v-fos FBJ murine osteosarcoma viral oncogene & & R68857 & ESTs & +2.4 \\
\hline & homolog & -2.4 & J04456 & galectin 1 & +2 \\
\hline \multirow[t]{2}{*}{ X97198 } & receptor phosphatase $\mathrm{PCP}-2$ & -2.4 & N34956 & frizzled homolog 7 & +2.4 \\
\hline & & & U04343 & T lymphocyte activation antigen CD86 precursor & +2 \\
\hline
\end{tabular}

Diff. Expr., Differential Expression. “-” indicates suppression and “+” indicates activation of expression in HPV31 cells.

was not changed by the presence of HPV genes. However, the expression of 178 ESTs (2.5\% of total ESTs examined) was increased by between 2 to 3 fold by HPV31, with no activation more than 3.2 fold observed. In addition, the expression of 150 ESTs (2.1\%) was decreased by at least two fold in HPV31 cells, with the largest change being 11.5 fold. The annotations of genes that were affected by more than 2.4 fold are listed in Table 1. The entire list of genes examined and the level of differential expression in normal and in HPV31 cells can be found at http://bugs.mimnet.nwu.edu/laimins Jab/chang [4]. 
From this analysis, the genes that were up-regulated in HPV31 cells were found to be ESTs with unknown functions, and the small number of known genes that were increased at significant level are also listed in Table 1 . However, the number of genes in that category is not large enough for us to discern any pattern of activation of specific families of genes. Notably, no E2F, or E2F inducible genes were activated significantly in HPV31 cells.

In contrast to genes that were up-regulated, it was simple to identify families of genes down-regulated in HPV31 cells. These can be divided into three categories: genes that are negative regulators of cell growth, genes that are specifically expressed in keratinocytes, and genes that are induced by interferon (IFN). The first category includes p21, Mad and transgelin. The expression of $\mathrm{p} 21$ is dependent on $\mathrm{p} 53$, and its reduced expression is consistent with the fact that high-risk HPV E6 protein inactivates $\mathrm{p} 53$ and thereby reduces the level of p21 expression [9]. Mad interacts with Max and antagonizes the proliferating effect of Myc/Max complex [1] which may play a role in activating telomerase [30]. Transgelin is a gene that is highly expressed in senescent cells, though the function is still not clear [28]. The second category we found to be repressed includes small proline rich protein SPRK, and SprII, defensin, desmocollin 2, desmoplakin, and stratifin [14,17,22,24, 29,31]. The role of these keratinocyte specific proteins in HPV pathogenesis is not clear. One can envision that by altering the expression of these genes, the cellular environment of the natural host of HPV is therefore changed in terms of response to stress, cell-cell contact, and altered differentiation program.

The third category of genes repressed by HPV includes those involved in the interferon pathway. These genes represent at least $14 \%$ of the total genes that were negatively regulated by 2.3 fold or more in HPV 31 infected cells. This group includes genes that showed the strongest changes: myxovirus resistance 1 (MxA, 11.5 fold), IFN- $\alpha$-inducible $11.5 \mathrm{KDa}$ protein (10.1 fold), and IFI 56 (9.6 fold). Among the IFN-inducible genes affected by HPV infection is the major regulator of IFN responsive pathway, Stat-1 (Signal Transducer and Activator of Transcription 1, which was repressed by 3.5 fold) [6]. Down-regulation of the basal level expression of IFN responsive genes in HPV31 cells could be largely the result of reduced basal level of Stat-1 expression. Further analysis has demonstrated that HPV31 cells showed a delayed response to IFN- $\alpha$ in terms of the induction of Stat-1 and MxA RNA. However, upon longer exposure to higher does of IFN- $\alpha$, the response reached the same level as in uninfected cells. It has been shown that high-risk HPVs interfere with the IFN response in several ways, by blocking interferon synthesis [25], or by blocking the function of Stat-1 posttranslationally $[2,18]$. However, suppression of basal level of Stat-1 expression by HPV has not been reported previously, although Stat-1 activity can be regulated at a post-traslational level. The reduced basal level of Stat-1RNA and protein did provide an advantage for HPV replication by delaying the cellular response to interferon. This delay could be very significant for the virus in evading immune surveillance. It has been postulated that reduced level of Stat-1 may also contribute to tumor progression. We are currently investigating the mechanism of Stat-1 gene suppression. Preliminary data suggested that both Stat-1 promoter inactivation and Stat-1 protein turn over rate may play important roles in regulating Stat-1 activity in HPV31 cells. The role of individual viral genes in these processes is being examined.

These studies demonstrate the utility of applying microarray analysis to HPV positive cells. Such studies can identify new markers of viral infection and potentially prognostic markers of disease progression. A more thorough analysis of biopsy materials and changes induced by other HPV types is needed to make the studies complete.

\section{References}

[1] D.E. Ayer, L. Kretzner and R.N. Eisenman, Mad: a heterodimeric partner for Max that antagonizes Myc transcriptional activity, Cell 72 (1993), 211-222.

[2] P. Barnard and N.A.J. McMillan, The human papillomavirus E7 oncoprotein abrogates signaling mediated by interferon- $\alpha$, Virology 259 (1999), 305-313.

[3] V. Bouvard, A. Storey, D. Pim and L. Banks, Characterization of the human papillomavirus E2 protein: evidence of trans-activation and trans-repression in cervical keratinocytes, EMBO Journal 13 (1994), 5451-5459.

[4] Y.E. Chang and L.A. Laimins, Mcroarray anlaysis identifies interferon-inducible genes and Stat-1 as major transcriptional targets of human papillomavirus type 31, Journal of Virology 74 (2000), 4147-4182.

[5] S. Cheng, G.D. Schmidt, T. Murant, T.R. Broker and L.T. Chow, Differentiation-dependent up-regulation of the human papillomavirus E7 gene reactivates cellular DNA replication in suprabasal differentiated keratinocytes, Genes \& Development 9 (1995), 2335-2349.

[6] J.E.J. Darnell, I.M. Kerr and G.R. Stark, Jak-STAT pathways and transcriptional activation in response to IFNs and other extracellular signaling proteins, Science 264 (1994), 14151421.

[7] S.C. Dollard, J.L. Wilson, L.M. Demeter, W. Bonnez, R.C. Reichman, T.R. Broker and L.T. Chow, Production of human 
papillomavirus and modulation of the infectious program in epithelial raft cultures, Genes \& Development 6 (1992), 11311142.

[8] N. Dyson, P.M. Howley, K. Munger and E. Harlow, The human papillomavirus-16 E7 oncoprotein is able to bind to the retinoblastoma gene product, Science 243 (1989), 934-937.

[9] W. El-Deiry, T. Tokino, V. Velculescu, D. Levy, R. Parson, J. Trent, D. Lin, W. Mercer, K. Kinzler and B. Vogelstein, WAF1, a potential mediator of p53 tumor suppression, Cell 75 (1993), 817-825.

[10] M.G. Frattini, H.B. Lim, J. Doorbar and L.A. Laimins, Induction of human papillomavirus type 18 late gene expression and genomic amplification in organotypic cultures from transfected DNA templates, Journal of Virology 71 (1997), 7068-7072.

[11] P.M. Howley, Papillomavirinae: the viruses and their replication, in: Fundamental Virology, B.N. Fields, D.M. Knipe and P.M. Howley, eds, Raven Press, New York, 1996, pp. 947-978.

[12] J.M. Huibregtse, M. Scheffner and P.M. Howley, A cellular protein mediates association of p53 with the E6 oncoprotein of human papillomavirus types 16 or 18, EMBO Journal 10 (1991), 4129-4135.

[13] V.R. Iyer, M.B. Eisen, D.T. Ross, G. Schuler, T. Moore, J.C.F. Lee, J.M. Trent, L.M. Staudt, J.J. Hudson, M.S. Boguski, D. Lashkari, D. Shalon, D. Botstein and P.O. Brown, The transcriptional program in the response of human fibroblast to serum, Science 283 (1999), 83-87.

[14] T. Kartasova and P. Van De Putte, Isolation, characterization, and UV-stimulated expression of two families of genes encoding polypeptides of related structure in human epidermal keratinocytes, Molecular and Cellular Biology 8 (1988), 21952203.

[15] L.A. Laimins, The biology of human papillomaviruses: from warts to cancer, Infectious Agents and Diseases 2 (1993), 7486.

[16] P. Leechanachai, L. Banks, F. Moreau and G. Matlashewski, The E5 gene from human papillomavirus type 16 is an oncogene which enhances growth factor-mediated signal transduction to the nucleus, Oncogene 7 (1992), 19-25.

[17] H. Leffers, P. Madsen, H.H. Rasmussen, B. Honore, A.H. Andersen, E. Walbum, J. Vandekerckhove and J.E. Celis, Molecular cloning and expression of the transformation sensitive epithelial marker stratifin, Journal of Molecular Biology 231 (1993), 982-998.

[18] S. Li, S. Labrecque, M.C. Gauzzi, A.R. Cuddihy, A.H. Wong, S. Pellegrini, G.J. Matlashewski and A.E. Koromilas, The human papilloma virus (HPV)-18 E6 oncoprotein physically associates with Tyk2 and impairs Jak-STAT activation by interferon-alpha, Oncogene 18 (1999), 5727-5737.

[19] D.R. Lowy, R. Kirnbauer and J.T. Schiller, Genital human papillomavirus infection. [Review], Proc. Natl. Acad. Sci. USA 91 (1994), 2436-2440.
[20] L.G. Martin, G.W. Demers and D.A. Galloway, Disruption of the G1/S transition in human papillomavirus type 16 E7expressing human cells is associated with altered regulation of cyclin E, Journal of Virology 72 (1998), 975-985.

[21] A.A. McBride, H. Romanczuk and P.M. Howley, The papillomavirus E2 regulatory proteins, Journal of Biological Chemistry 266 (1991), 18411-18414.

[22] P.B.J. McCray and L. Bentley, Human airway epithelia express a $\beta$-defensin, America Journal of Respiratory Cell Molecular Biology 16 (1997), 343-349.

[23] C. Meyers, M.G. Frattini, J.B. Hudson and L.A. Laimins, Biosynthesis of human papillomavirus from a continuous cell line upon epithelial differentiation, Science 257 (1992), 971973.

[24] A.E. Parker, G.N. Wheeler, J. Arnemann, S.C. Pidsley, P. Ataliotis, C.L. Thomas, D.A. Rees, A.I. Magee and R.S. Buxton, Desmosomal glycoproteins II and III, The Journal of Biological Chemistry 266 (1991), 10438-10445.

[25] L.V. Ronco, A.Y. Karpova, M. Vidal and P.M. Howley, Human papillomavirus 16 E6 oncoprotein binds to interferon regulatory factor-3 and inhibits its transcriptional activity, Genes and Development 12 (1998), 2061-2072.

[26] M. Scheffner, J.M. Huibregtse, R.D. Vierstra and P.M. Howley, The HPV-16 E6 and E6-AP complex functions as a ubiquitinprotein ligase in the ubiquitination of p53, Cell 75 (1993), 495-505.

[27] M. Scheffner, B.A. Werness, J.M. Huibregtse, A.J. Levine and P.M. Howley, The E6 oncoprotein encoded by human papillomavirus types 16 and 18 promotes the degradation of p53, Cell 63 (1990), 1129-1136.

[28] R. Thweatt, C.K.J. Lumpkin and S. Goldstein, A novel gene encoding a smooth muscle protein is overexpressed in senescent human fibroblasts, Biochemical and Biophysical Research Communications 187 (1992), 1-7.

[29] M.L.A. Virata, R.M. Wagner, D.A.D. Parry and K.J. Green, Molecular structure of the human desmoplakin I and II amino terminus, Proc. Natl. Acad. Sci. USA 89 (1992), 544-548.

[30] J. Wang, L.Y. Xie, S. Allan, D. Beach and G.J. Hannon, Myc activates telomerase, Genes and Development 12 (1998), 1769-1774.

[31] D. Yang, O. Chertov, S.N. Bykovskaia, Q. Chen, M.J. Buffo, J. shogan, M. Anderson, J.M. Schroder, J.M. Wang, O.M.Z. Howard and J.J. Oppenheim, $\beta$-defensins: linking innate and adaptive immunity through dendritic and T cell CCR6, Science 286 (1999), 525-528.

[32] H. Zhu, J.P. Cong, G. Mamtora, T. Gingeras and T. Shenk, Cellular gene expression altered by human cytomegalovirus: global monitoring with oligonucleotide arrays, Proc. Natl. Acad. Sci. USA 95 (1998), 14470-14475.

[33] H. zur Hausen and E.M. de Villiers, Human papillomaviruses. [Review], Апnи. Rev. Microbiol. 48 (1994), 427-447. 


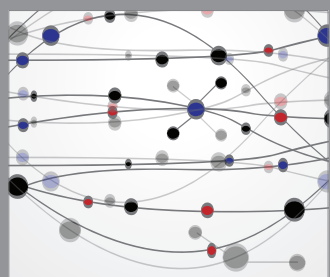

The Scientific World Journal
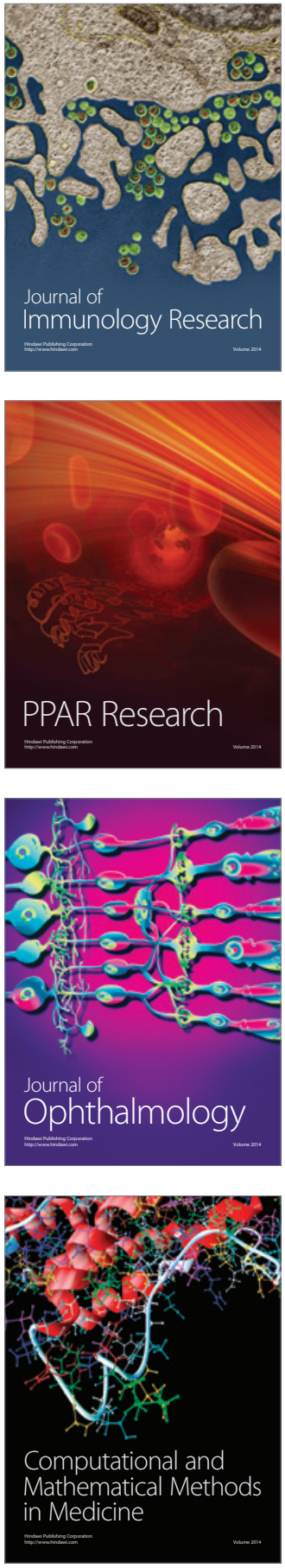

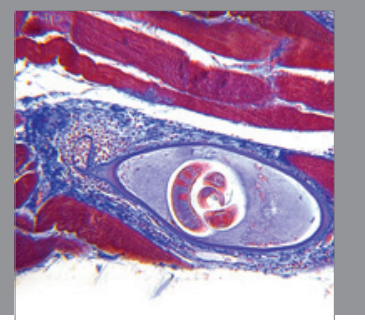

Gastroenterology

Research and Practice
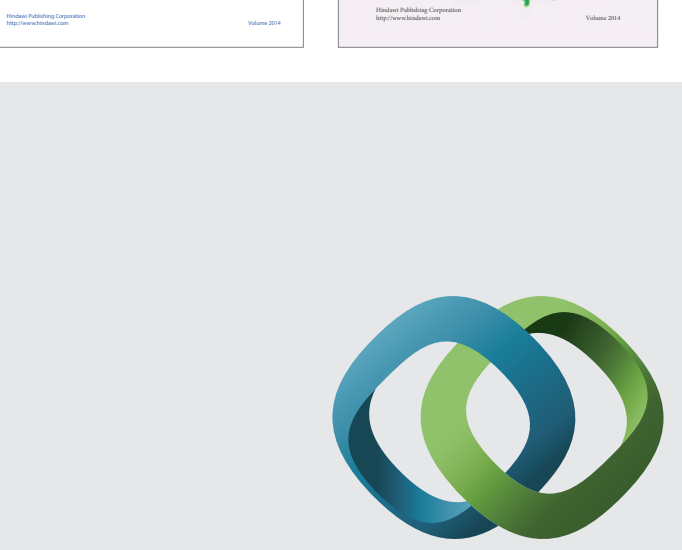

\section{Hindawi}

Submit your manuscripts at

http://www.hindawi.com
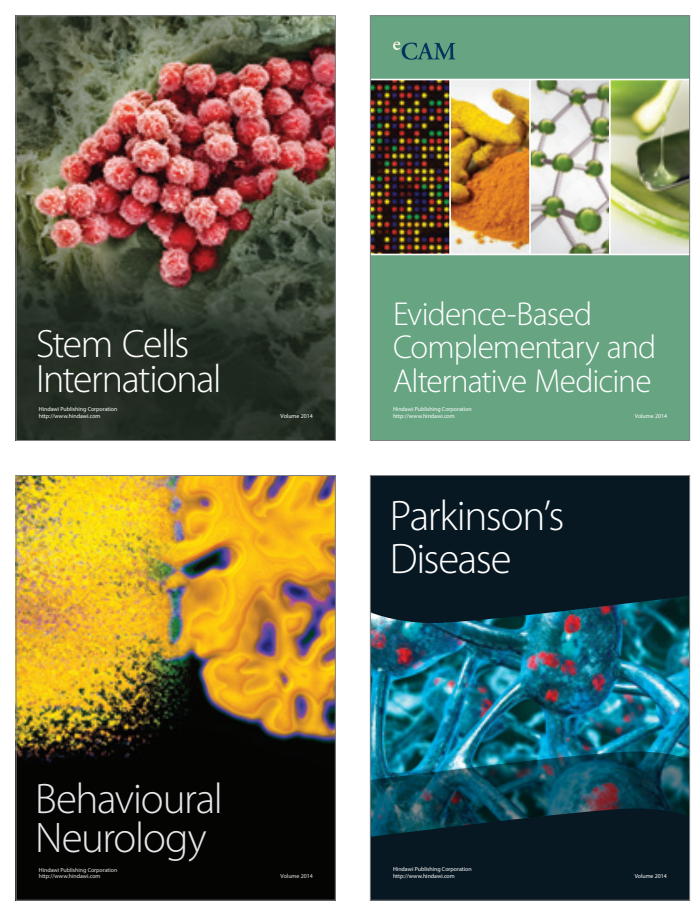

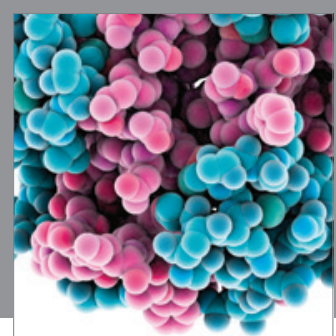

Journal of
Diabetes Research

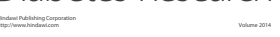

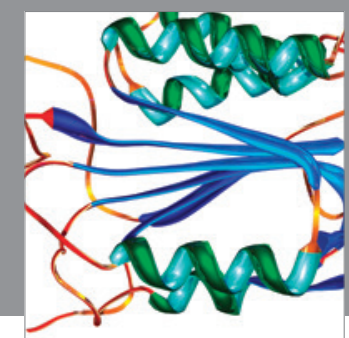

Disease Markers
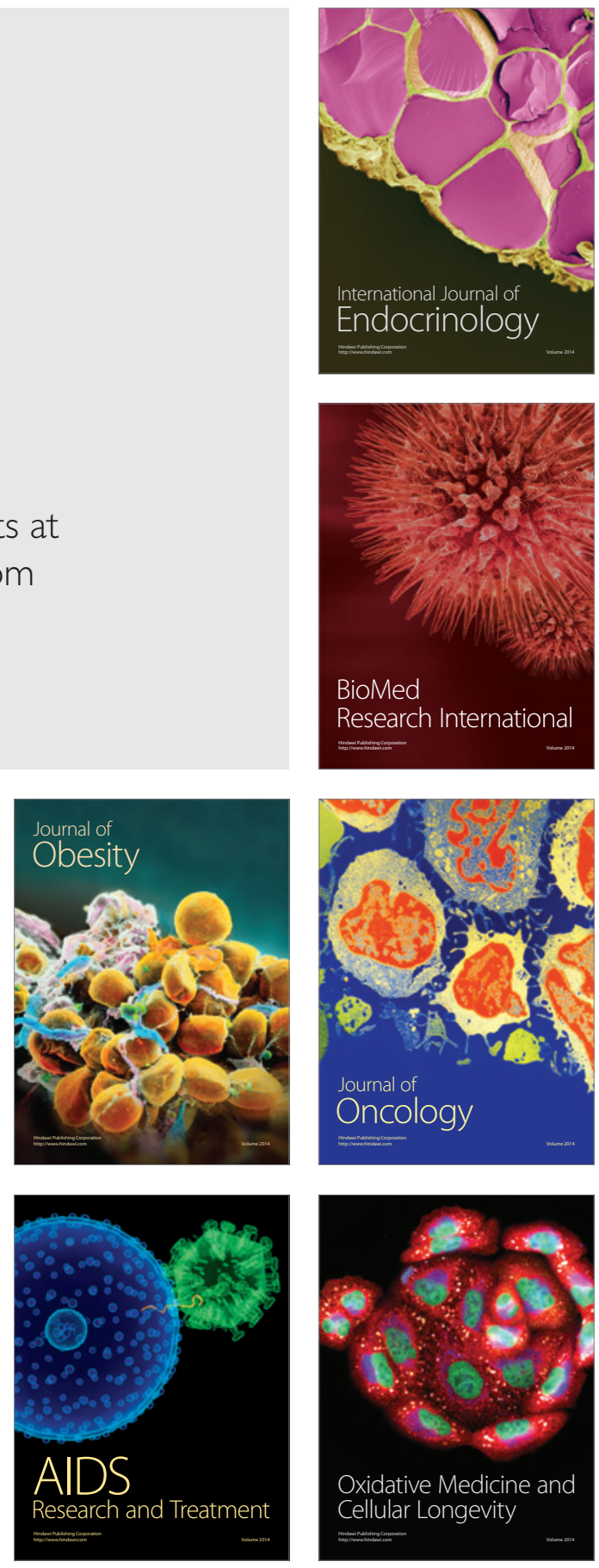